\title{
Interference of propofol with signal transducer and activator of transcription 5 activation and cardioprotection by remote ischemic preconditioning during coronary artery bypass grafting
}

\author{
Eva Kottenberg, MD, ${ }^{\mathrm{a}}$ Judith Musiolik, PhD, ${ }^{\mathrm{b}}$ Matthias Thielmann, MD, ${ }^{\mathrm{c}}$ Heinz Jakob, MD, ${ }^{\mathrm{c}}$ \\ Jürgen Peters, $\mathrm{MD},{ }^{\mathrm{d}}$ and Gerd Heusch, $\mathrm{MD}, \mathrm{PhD}^{\mathrm{e}}$
}

\begin{abstract}
Objective: Remote ischemic preconditioning protects the myocardium from ischemia/reperfusion injury. We recently identified protection by remote ischemic preconditioning to be associated with the activation of signal transducer and activator of transcription 5 in left ventricular biopsy specimens of patients undergoing coronary artery bypass grafting during isoflurane anesthesia. Because remote ischemic preconditioning did not protect the heart during propofol anesthesia, we hypothesized that propofol anesthesia interferes with signal transducer and activator of transcription 5 activation.
\end{abstract}

\begin{abstract}
Methods: In a randomized, single-blind, placebo-controlled, prospective study, we analyzed an array of established cardioprotective proteins during propofol anesthesia with or without remote ischemic preconditioning in 24 nondiabetic patients with 3-vessel coronary artery disease.

Results: Remote ischemic preconditioning $(\mathrm{n}=12)$ compared with no remote ischemic preconditioning $(\mathrm{n}=12)$ failed to decrease the area under the troponin I time curve $(273 \pm 184 \mathrm{ng} / \mathrm{mL} \times 72$ hours vs $365 \pm 301 \mathrm{ng} / \mathrm{mL} \times 72$ hours; $P=.374)$. Although phosphorylation of several protein kinases was increased from baseline to reperfusion, signal transducer and activator of transcription 5 phosphorylation was not increased and was not different between the remote ischemic preconditioning and no remote ischemic preconditioning groups.
\end{abstract}

Conclusions: Remote ischemic preconditioning during propofol anesthesia did not evoke either signal transducer and activator of transcription 5 activation or cardioprotection, implying interaction of propofol with cardioprotective signaling upstream of signal transducer and activator of transcription 5. (J Thorac Cardiovasc Surg 2014; $147: 376-82)$

In classic ischemic preconditioning, defined by the protection mediated by brief episodes of ischemia/reperfusion, a whole array of trigger and mediator molecules are involved. For many of these molecules, pharmacologic recruitment has been attempted. ${ }^{1}$ In addition to volatile anesthetics, opioids, the vasopressor phenylephrine, adenosine, and bradykinin have all been reported to evoke cardioprotection. ${ }^{1}$ Remote ischemic preconditioning (RIPC), ${ }^{2,3}$ an attractive alternate method to classic ischemic preconditioning for decreasing perioperative myocardial damage, can also protect the human myocardium from ischemia/reperfusion injury, as evidenced in patients undergoing elective coronary artery bypass grafting

From the Klinik für Anästhesiologie und Intensivmedizin, ${ }^{\mathrm{a}}$ Institut für Pathophysiologie, ${ }^{\mathrm{b}}$ Klinik für Thorax- und Kardiovaskuläre Chirurgie, ${ }^{\mathrm{c}}$ Klinik für Anästhesiologie und Intensivmedizin, ${ }^{\mathrm{d}}$ and Institut für Pathophysiologie, ${ }^{\mathrm{e}}$ Universität Duisburg-Essen, Universitätsklinikum Essen, Essen, Germany.

Disclosures: Authors have nothing to disclose with regard to commercial support.

Received for publication Oct 14, 2012; revisions received Dec 9, 2012; accepted for publication Jan 11, 2013; available ahead of print March 4, 2013.

Address for reprints: Eva Kottenberg, DEAA, Klinik für Anästhesiologie und Intensivmedizin, Universitätsklinikum Essen, Hufelandstr 55, Essen D-4511, Germany

(E-mail: eva.kottenberg@uni-duisburg-essen.de).

$0022-5223 / \$ 36.00$

Copyright $($ c 2014 by The American Association for Thoracic Surgery

http://dx.doi.org/10.1016/j.jtcvs.2013.01.005
$(\mathrm{CABG})^{4-6}$ or percutaneous coronary interventions. ${ }^{7,8}$ The lack of protection found in several recent studies ${ }^{9-11}$ possibly relates to the anesthetic regimens used. ${ }^{12}$ We recently reported decreased postoperative troponin I concentrations after RIPC only in patients undergoing CABG with isoflurane but not in those who received propofol anesthesia. $^{13}$

The signal transduction of cardioprotection by RIPC, including the transmission of the protective signal from the distant organ and the intracellular pathways in cardiomyocytes, is still unclear. We recently observed cardioprotection by RIPC in patients undergoing CABG with previous RIPC under isoflurane anesthesia and identified an increase in tyrosine 694 phosphorylation of signal transducer and activator of transcription (STAT)5 in left ventricular (LV) biopsy specimens. STAT5 phosphorylation increased from baseline to early reperfusion only in the patients who had undergone RIPC but not in the control patients. However, a causal role for the observed STAT5 activation in cardioprotection remains to be established. ${ }^{1,14}$

Because we observed protection by RIPC during isoflurane, but not during propofol, anesthesia, ${ }^{13}$ we hypothesized that propofol interferes with STAT5 activation, which was shown to be activated in our previous study of cardioprotection by RIPC with isoflurane anesthesia. Accordingly, we 

Abbreviations and Acronyms
$\mathrm{CABG}=$ coronary artery bypass grafting
$\mathrm{cTnI}=$ cardiac troponin I
$\mathrm{cTnI}=$ area under the $\mathrm{cTnI}$ time curve
AUC
$\mathrm{CPB}=$ cardiopulmonary bypass
$\mathrm{LV} \quad=$ left ventricular
RIPC = remote ischemic preconditioning
STAT $=$ signal transducer and activator of transcription

assessed in a randomized, single-blind, placebo-controlled, prospective study, the effects of RIPC on STAT5 activation and the serum troponin I concentrations in nondiabetic patients undergoing $\mathrm{CABG}$ during propofol anesthesia.

\section{METHODS \\ Patients}

The present study is part of an ongoing multiprotocol study (ClinicalTrials.gov NCT01406678) addressing the effects and mechanisms of RIPC and anesthesia on the cardiac troponin concentrations in patients undergoing $\mathrm{CABG}$. The institutional ethics committee approved the study, and all patients provided written informed consent. The present cohort of 24 patients with 3-vessel coronary artery disease scheduled for CABG (Table 1) was enrolled from June 2010 to December 2011. They were randomized on the day of surgery to receive, under propofol/sufentanil anesthesia, either a RIPC protocol, consisting of repetitive left upper arm ischemia (3 cycles of 5-minute cuff occlusion/5-minute reperfusion each), or no RIPC (cuff uninflated). None of the patients, data, or samples obtained in our previous studies of RIPC ${ }^{6,13,14}$ were included in the present study.

All patients older than 18 years who were scheduled for elective, isolated, first-time CABG for 3-vessel coronary artery disease were eligible for the present study. The exclusion criteria were any type of diabetes mellitus (controlled by diet, oral drugs, or insulin), renal insufficiency (serum creatinine $>2 \mathrm{mg} / \mathrm{dL}$ ), peripheral vascular disease affecting the upper limbs, acute coronary syndrome, acute or recent myocardial infarction, preoperative inotropic support before the induction of anesthesia, any type of mechanical assist device, any condition potentially increasing the preoperative cardiac troponin I (cTnI) level (eg, coronary interventions within the previous 6 weeks), or any type of emergency surgery, combined CABG/ valve surgery, or any previous cardiac operations.

\section{General Procedures}

General anesthesia was induced by sufentanil $(1 \mu \mathrm{g} / \mathrm{kg}$, Sufenta; Janssen-Cilag, Neuss, Germany) and etomidate $(0.3 \mathrm{mg} / \mathrm{kg}$, Hypnomidat; Janssen-Cilag, Neuss, Germany), followed by rocuronium $(0.6 \mathrm{mg} / \mathrm{kg}$, Esmeron; Organon Teknika, Oberschlei $\beta$ heim, Germany). Anesthesia was maintained by continuous propofol infusion $(0.07-0.15 \mathrm{mg} / \mathrm{kg} / \mathrm{min})$, with additional sufentanil injected at the discretion of the responsible anesthesiologist, as required. During extracorporal circulation, the patients continued to receive a propofol infusion.

Surgical revascularization was performed in all patients after a median sternotomy. Hypothermic $\left(30^{\circ} \mathrm{C}-33^{\circ} \mathrm{C}\right)$ cardiopulmonary bypass $(\mathrm{CPB})$ was instituted through an ascending aortic cannula and a 2-stage right atrial cannula. After ascending aortic crossclamping, Bretschneider's cardioplegia was introduced. After completion of the distal CABG anastomoses, the aortic crossclamp was released, and cardiac reperfusion ensued. After rewarming the patient to $37^{\circ} \mathrm{C}$ and separation from $\mathrm{CPB}$, reversal of heparin by protamine sulphate $(3 \mathrm{mg} / \mathrm{kg})$, and sternal closure, the patients were transferred to the intensive care unit. ${ }^{13}$

\section{Troponin I}

To assess myocardial injury, cTnI was measured (Immunoassay Dimension Flex, Dade Behring GmbH, Marburg, Germany) at specified times for 72 hours after CABG in an accredited laboratory. The serum cTnI levels were determined preoperatively and $1,6,12,24,48$, and 72 hours postoperatively, and the area under the cTnI time curve (cTnI AUC) was determined.

\section{Western Blot Analyses}

In each patient, transmural myocardial biopsy specimens of 2 to $5 \mathrm{mg}$ each were harvested using a Tru-Cut biopsy needle (Cardinal Health, Dublin, Ohio) from the LV perfusion territory undergoing revascularization, quickly frozen in liquid nitrogen, and stored at $-80^{\circ} \mathrm{C}$ until analysis. The first biopsy specimen was taken at baseline before starting CPB, the second after 10 minutes of myocardial reperfusion after aortic declamping. Western blot analysis was performed with antibodies against the phosphorylated and total forms of several established signaling proteins, including protein kinase $\mathrm{C}$, p38 mitogen-activated protein kinase, vasodilatorstimulated phosphoprotein as a substrate of protein kinase G, endothelial nitric oxide synthase, protein kinase $B$, extracellular-regulated kinase, p70 ribosomal S6 protein kinase, glycogen synthase kinase $3 \beta$, STAT3, and STAT5. ${ }^{14}$ The immunoreactivities of the phosphorylated proteins were normalized to those of the respective total proteins.

Two aliquots of each sample were analyzed separately on 2 different gels; therefore, these data can differ. The baseline and reperfusion samples were compared within the no RIPC and RIPC group on 1 gel each, and the baseline and reperfusion samples were compared between the no RIPC and RIPC group on 1 gel each.

\section{Study Protocol}

After induction of anesthesia and endotracheal intubation, a standard blood pressure cuff was inflated to $200 \mathrm{~mm} \mathrm{Hg}$ (ie, always in excess of the contralateral systolic radial artery pressure) for 5 minutes by a resident assigned to the case and not involved in either randomization or data assessment. As a control, a cuff was placed around the left upper arm but left uninflated. Three cycles of 5-minute left upper arm ischemia were separated by 5 -minute intervals of reperfusion by deflating the cuff. The RIPC protocol was always completed before the skin incision.

The data from 24 patients fulfilling the enrollment criteria were analyzed in a single-blind, randomized protocol. Before the trial, computer-generated randomization schedules were generated and placed in sequentially numbered sealed envelopes. The laboratory personnel measuring the troponin concentrations, patients, surgeons, echocardiographers, and critical care teams were unaware of the treatments assigned for the study duration. The resident anesthetists, who applied the protocol by inflating or not inflating the cuff could not be blind to the group assignment but had no part in the data sampling or analysis.

\section{Statistical Analysis}

The patient characteristics and cTnI concentrations are expressed as numbers, frequencies, or mean \pm standard deviation. The data were compared using a 2-way analysis of variance and Student's 2-sided $t$ test for unpaired samples. A chi-square test was used to compare the categorical variables. The immunoreactivities on the same gels were compared by paired (within groups) or unpaired (between groups) $t$ tests.

The following a priori null hypothesis was tested using the cTnI AUC as a primary and the STAT5 phosphorylation as a secondary criterion: (1) no difference exists in cTnI AUC with and without RIPC during propofol 
TABLE 1. Demographic and perioperative data stratified by RIPC

\begin{tabular}{|c|c|c|c|}
\hline \multirow[b]{2}{*}{ Variable } & \multicolumn{2}{|c|}{ Propofol anesthesia } & \multirow[b]{2}{*}{$P$ value } \\
\hline & No RIPC & RIPC & \\
\hline \multicolumn{4}{|l|}{ Patient characteristics } \\
\hline Patients (n) & 12 & 12 & \\
\hline Age $(y)$ & $66 \pm 9$ & $65 \pm 9$ & .42 \\
\hline Gender (n) & & & .11 \\
\hline Male & 11 & 10 & \\
\hline Female & 1 & 2 & \\
\hline Weight $(\mathrm{kg})$ & $79 \pm 10$ & $89 \pm 14$ & .30 \\
\hline Height $(\mathrm{cm})$ & $174 \pm 6$ & $174 \pm 7$ & .24 \\
\hline \multicolumn{4}{|l|}{ Intraoperative variables } \\
\hline CPB time $(\min )$ & $111 \pm 26$ & $109 \pm 18$ & .82 \\
\hline Crossclamping time (min) & $70 \pm 20$ & $70 \pm 17$ & .54 \\
\hline Total anesthesia time $(\mathrm{min})$ & $326 \pm 61$ & $348 \pm 54$ & .63 \\
\hline $\begin{array}{l}\text { Adrenaline dosage (end of } \\
\text { surgery) }(\mu \mathrm{g} / \mathrm{kg} / \mathrm{min})\end{array}$ & $0.05 \pm 0.02$ & $0.05 \pm 0.02$ & .78 \\
\hline Sufentanil dosage $(\mu \mathrm{g} / \mathrm{kg} / \mathrm{min})$ & $0.01 \pm 0.002$ & $0.01 \pm 0.003$ & .86 \\
\hline $\begin{array}{l}\text { Neosynephrine dosage } \\
\quad(\mu \mathrm{g} / \mathrm{kg} / \mathrm{min})\end{array}$ & $0.03 \pm 0.02$ & $0.02 \pm 0.02$ & .74 \\
\hline Volume of cardioplegia $(\mathrm{mL})$ & $1433 \pm 320$ & $1525 \pm 122$ & .56 \\
\hline In-hospital mortality (n) & 0 & 0 & 1.00 \\
\hline \multicolumn{4}{|l|}{ Risk factors and comorbidities (n) } \\
\hline Hypertension & 10 & 11 & .82 \\
\hline Hyperlipidemia & 11 & 10 & .33 \\
\hline Obesity & 10 & 9 & .28 \\
\hline Current smoker & 6 & 5 & .35 \\
\hline \multicolumn{4}{|l|}{ Antihypertensive medications (n) } \\
\hline$\beta$-Blocker & 10 & 10 & .79 \\
\hline Calcium channel blocker & 1 & 6 & .15 \\
\hline ACEI/ARB & 10 & 8 & .67 \\
\hline Diuretics & 2 & 1 & .83 \\
\hline
\end{tabular}

Data are presented as numbers or mean \pm standard deviation. RIPC, Remote ischemic preconditioning; $C P B$, cardiopulmonary bypass; $A C E I$, angiotensin-converting enzyme inhibitor; $A R B$, angiotensin receptor blocker.

anesthesia; or (2) no increased STAT5 phosphorylation occurs with RIPC during propofol anesthesia.

\section{RESULTS}

A total of 35 patients with 3-vessel coronary artery disease were initially screened from June 2010 to December 2011, of whom 29 were eligible for study enrollment. Six of these patients were ineligible for enrollment because of diabetes mellitus. All 29 patients agreed to participate and were randomized to receive RIPC or no RIPC under propofol anesthesia. After randomization, 5 additional patients had to be excluded. In 4 patients, the protein yield from a LV biopsy was insufficient and 1 patient was withdrawn because of an unclear biopsy assignment to baseline or reperfusion.

Accordingly, the data from 24 patients $(21$ men and 3 women; mean age, 66 years; range, 53-80 years; weight, $84.9 \pm 3 \mathrm{~kg}$, height, $174 \pm 7 \mathrm{~cm}$ ), who had undergone propofol anesthesia with either RIPC $(\mathrm{n}=12)$ or no RIPC $(\mathrm{n}=12)$, were analyzed.

The characteristics of the study cohorts are listed in Table 1. No differences were found between the cohorts

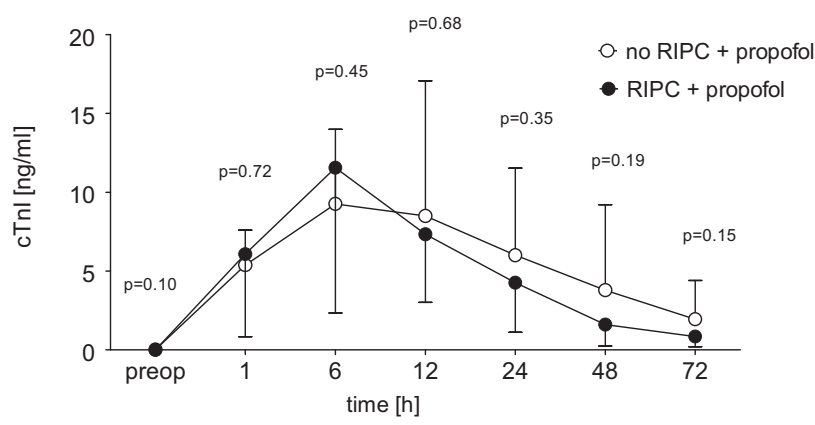

FIGURE 1. Time course of serum cardiac troponin I ( $c$ TnI) before (preop) and 1, 6, 12, 24, 48, and 72 hours after coronary artery bypass grafting (mean \pm standard deviation) with (black circles, $\mathrm{n}=12$ ) or without (open circles, $\mathrm{n}=12$ ) remote ischemic preconditioning $(R I P C)$ under propofol anesthesia.

in patient characteristics or intraoperative data, such as total anesthesia time, CPB and crossclamp times, inotropic support at the end of surgery, cardioplegia volume administered, or in-hospital mortality. Although the same number of patients in each group received $\beta$-blockers, more patients in the RIPC than in the no RIPC group took calcium channel blockers.

\section{RIPC During Propofol Anesthesia}

The preoperative $\mathrm{cTnI}$ level did not differ between the 2 groups $(P=.10)$. RIPC did not significantly alter the cTnI AUC (RIPC, $273 \pm 184 \mathrm{ng} / \mathrm{mL} \times 72$ hours; no RIPC, $365 \pm 301 \mathrm{ng} / \mathrm{mL} \times 72$ hours; $P=.374) ; \mathrm{cTnI}$ at 1 $(P=.72), 6(P=.45), 12(0.68), 24(P=.35), 48$ $(P=.19)$, and $72(P=.15)$ hours after CABG surgery; or individual peak cTnI (RIPC, $11.7 \pm 9.2 \mathrm{ng} / \mathrm{mL}$; no RIPC, $11.6 \pm 8.3 \mathrm{ng} / \mathrm{mL}, P=.988$; Figure 1). With an intention-to-treat analysis of all patients subjected to the randomized protocol $(\mathrm{n}=29)$, RIPC also did not alter the cTnI AUC (RIPC [ $\mathrm{n}=15$ ], $285 \pm 201 \mathrm{ng} / \mathrm{mL} \times 72$ hours; no RIPC [n $=14$ ], $330 \pm 290 \mathrm{ng} / \mathrm{mL} \times 72$ hours; $P=.352$ ).

\section{Protein Phosphorylation With and Without RIPC}

The concentration of total proteins did not differ significantly between the 2 groups, either at baseline or after reperfusion (Table 2). Likewise, the concentration of phosphorylated proteins did not differ between the 2 groups at baseline (Table 3).

The phosphorylation of $\mathrm{p} 38$, protein kinase $\mathrm{B}$, extracellular signal-regulated kinase $1 / 2$, p70 ribosomal S6 protein kinase, glycogen synthase kinase $3 \beta$, and STAT3 at tyrosine 705 and serine 727 was significantly increased from baseline to early reperfusion but was not different between groups with and without RIPC. STAT5 phosphorylation was not increased from baseline to early reperfusion in patients with and without RIPC (Table 2). This lack of effect in STAT5 phosphorylation was confirmed with 2 different antibodies (Figure 2). 
TABLE 2. Total protein levels during baseline and reperfusion, with and without RIPC

\begin{tabular}{|c|c|c|c|c|c|c|}
\hline \multirow[b]{3}{*}{ Variable } & \multicolumn{6}{|c|}{ Total protein/Ponceau staining } \\
\hline & \multicolumn{3}{|c|}{ RIPC } & \multicolumn{3}{|c|}{ No RIPC } \\
\hline & Baseline & Reperfusion & $P$ value & Baseline & Reperfusion & $P$ Value \\
\hline $\mathrm{PKC} \alpha$ & $1.10 \pm 0.145$ & $1.21 \pm 0.078$ & .35 & $0.96 \pm 0.116$ & $1.05 \pm 0.174$ & .67 \\
\hline p38 & $0.43 \pm 0.074$ & $0.54 \pm 0.080$ & .24 & $0.83 \pm 0.071$ & $0.98 \pm 0.126$ & .16 \\
\hline VASP & $0.55 \pm 0.060$ & $0.81 \pm 0.159$ & .09 & $0.94 \pm 0.080$ & $1.10 \pm 0.159$ & .26 \\
\hline eNOS & $1.42 \pm 0.338$ & $0.77 \pm 0.211$ & .11 & $0.47 \pm 0.072$ & $0.48 \pm 0.065$ & .84 \\
\hline $\mathrm{AKT}$ & $1.14 \pm 0.142$ & $0.98 \pm 0.141$ & .13 & $0.61 \pm 0.081$ & $0.63 \pm 0.092$ & .78 \\
\hline ERK1/2 & $0.42 \pm 0.077$ & $0.38 \pm 0.067$ & .67 & $0.65 \pm 0.065$ & $0.76 \pm 0.095$ & .10 \\
\hline p70S6K & $0.40 \pm 0.062$ & $0.48 \pm 0.102$ & .57 & $0.49 \pm 0.079$ & $0.47 \pm 0.076$ & .68 \\
\hline GSK $3 \beta$ & $0.66 \pm 0.071$ & $0.61 \pm 0.088$ & .62 & $0.43 \pm 0.061$ & $0.39 \pm 0.057$ & .56 \\
\hline $\mathrm{STAT}_{\mathrm{tyr}}$ & $1.07 \pm 0.134$ & $1.17 \pm 0.165$ & .49 & $0.53 \pm 0.082$ & $0.63 \pm 0.099$ & .11 \\
\hline $\mathrm{STAT}_{\text {ser }}$ & $0.47 \pm 0.054$ & $0.55 \pm 0.096$ & .45 & $0.53 \pm 0.093$ & $0.52 \pm 0.105$ & .83 \\
\hline STAT5 A & $0.71 \pm 0.076$ & $0.78 \pm 0.085$ & .43 & $0.61 \pm 0.081$ & $0.71 \pm 0.100$ & .71 \\
\hline \multirow[t]{3}{*}{ STAT5 B } & $0.93 \pm 0.098$ & $0.97 \pm 0.086$ & .49 & $0.88 \pm 0.080$ & $0.81 \pm 0.061$ & .45 \\
\hline & \multicolumn{3}{|c|}{ Baseline } & \multicolumn{3}{|c|}{ Reperfusion } \\
\hline & RIPC & No RIPC & & RIPC & No RIPC & \\
\hline $\mathrm{PKC} \alpha$ & $0.79 \pm 0.082$ & $0.93 \pm 0.138$ & .47 & $0.45 \pm 0.045$ & $0.59 \pm 0.086$ & .17 \\
\hline p38 & $0.80 \pm 0.083$ & $1.02 \pm 0.116$ & .34 & $0.71 \pm 0.056$ & $0.73 \pm 0.105$ & .88 \\
\hline VASP & $0.45 \pm 0.054$ & $0.59 \pm 0.087$ & .23 & $0.68 \pm 0.130$ & $0.68 \pm 0.156$ & .99 \\
\hline eNOS & $0.71 \pm 0.086$ & $0.70 \pm 0.109$ & .94 & $0.41 \pm 0.044$ & $0.51 \pm 0.055$ & .18 \\
\hline $\mathrm{AKT}$ & $0.93 \pm 0.059$ & $0.85 \pm 0.106$ & .51 & $0.59 \pm 0.044$ & $0.63 \pm 0.072$ & .66 \\
\hline ERK1/2 & $0.68 \pm 0.072$ & $0.65 \pm 0.088$ & .72 & $0.58 \pm 0.063$ & $0.58 \pm 0.105$ & .98 \\
\hline p70S6K & $0.55 \pm 0.045$ & $0.46 \pm 0.058$ & .32 & $1.27 \pm 0.166$ & $1.53 \pm 0.221$ & .36 \\
\hline GSK $3 \beta$ & $0.78 \pm 0.083$ & $0.81 \pm 0.083$ & .85 & $1.47 \pm 0.131$ & $1.68 \pm 0.176$ & .34 \\
\hline $\mathrm{STAT}_{\mathrm{tyr}}$ & $0.86 \pm 0.079$ & $0.75 \pm 0.101$ & .32 & $0.66 \pm 0.052$ & $0.72 \pm 0.093$ & .53 \\
\hline $\mathrm{STAT}_{\text {ser }}$ & $0.76 \pm 0.060$ & $0.68 \pm 0.081$ & .49 & $1.33 \pm 0.113$ & $1.50 \pm 0.198$ & .46 \\
\hline STAT5 A & $0.53 \pm 0.094$ & $0.62 \pm 0.110$ & .52 & $0.83 \pm 0.120$ & $0.79 \pm 0.097$ & .77 \\
\hline STAT5 B & $0.34 \pm 0.046$ & $0.41 \pm 0.070$ & .43 & $0.73 \pm 0.110$ & $0.71 \pm 0.076$ & .88 \\
\hline
\end{tabular}

Baseline and reperfusion data are derived from separate gels and differ between upper and lower portions of table. Statistical comparisons made only for data from same gel. Ponceau staining used to normalize for protein loading of gels. RIPC, Remote ischemic preconditioning; $P K C \alpha$, protein kinase C $\alpha ; p 38$, p38 mitogen-activated protein kinase; $V A S P$, vasodilator-stimulated phosphoprotein; $e N O S$, endothelial nitric oxide synthase; $A K T$, protein kinase $\mathrm{B} ; E R K$, extracellular signal-regulated kinase; $p 70 S 6 K$, p70 ribosomal S6 protein kinase; GSK3 $\beta$, glycogen synthase kinase-3 $\beta$; STAT, signal transducer and activator of transcription; tyr, tyrosine; ser, serine.

\section{DISCUSSION}

In the present randomized, single-blind, placebo-controlled, prospective study, we have confirmed, in another cohort of nondiabetic patients undergoing elective CABG, the lack of cardioprotection by RIPC under propofol anesthesia that we previously reported. ${ }^{13}$ Furthermore, in contrast to the cardioprotection obtained by RIPC, along with STAT5 activation under isoflurane anesthesia, ${ }^{14}$ no STAT5 activation occurred under propofol anesthesia. This absence under propofol anesthesia of both cardioprotection and STAT5 activation confirms, not only that propofol somehow interferes with RIPC-mediated protection but also might suggest that this interference is located upstream of STAT5 activation.

\section{Study Limitations}

It is important to note that positive controls for a study such as the present one are needed. However, we have previously published 2 positive controls. We reported that STAT5 phosphorylation is increased in patients undergoing $\mathrm{CABG}$ with previous $\mathrm{RIPC}^{14}$ and also that protection by RIPC is achieved during isoflurane, but not during propofol, anesthesia. ${ }^{13}$ Given that propofol deprived patients of cardioprotection and that the analysis of STAT5 phosphorylation required LV biopsies, we did not repeat these positive controls just for additional confirmation.

None of the proteins previously implicated in cardioprotection was different with RIPC, except for STAT5 with isoflurane anesthesia. Potassium-adenosine triphosphate mitochondrial channels have been implicated in the mechanism of ischemic preconditioning. ${ }^{15,16}$ Mitochondrial adenosine triphosphate-sensitive potassium channels were not addressed in the present study, because their molecular identity has not yet been defined. Therefore, they were not amenable to protein analysis. The analysis of a role for mitochondrial adenosine triphosphate-sensitive potassium channels would require the use of specific agonists or antagonists, which was beyond the scope of the present study in humans. 
TABLE 3. Activation of signaling proteins by phosphorylation

\begin{tabular}{|c|c|c|c|c|c|c|}
\hline \multirow[b]{2}{*}{ Phosphoprotein/total protein } & \multicolumn{3}{|c|}{ RIPC } & \multicolumn{3}{|c|}{ No RIPC } \\
\hline & Baseline & Reperfusion & $P$ value & Baseline & Reperfusion & $P$ value \\
\hline $\mathrm{p}-\mathrm{PKC} \alpha / \beta / \mathrm{PKC} \alpha$ & $0.64 \pm 0.084$ & $0.68 \pm 0.085$ & .62 & $0.79 \pm 0.059$ & $0.86 \pm 0.052$ & .21 \\
\hline p-p38/p38 & $0.86 \pm 0.215$ & $4.08 \pm 0.723$ & .004 & $1.20 \pm 0.430$ & $2.20 \pm 0.249$ & .02 \\
\hline p-VASP/VASP & $1.08 \pm 0.130$ & $0.95 \pm 0.117$ & .41 & $0.52 \pm 0.065$ & $0.51 \pm 0.073$ & .90 \\
\hline p-eNOS/eNOS & $2.08 \pm 0.494$ & $2.53 \pm 0.364$ & .50 & $2.85 \pm 0.582$ & $2.15 \pm 0.383$ & .12 \\
\hline p-AKT/AKT & $0.09 \pm 0.009$ & $1.43 \pm 0.247$ & .00003 & $0.50 \pm 0.062$ & $1.74 \pm 0.370$ & .01 \\
\hline p-ERK1/2/ERK1/2 & $1.40 \pm 0.335$ & $3.31 \pm 0.470$ & .02 & $0.54 \pm 0.110$ & $0.90 \pm 0.105$ & .04 \\
\hline p-p70S6K/p70S6K & $0.31 \pm 0.050$ & $3.13 \pm 0.605$ & .0001 & $0.26 \pm 0.064$ & $1.84 \pm 0.174$ & .00001 \\
\hline p-GSK3 $\beta / G S K 3 \beta$ & $0.54 \pm 0.081$ & $1.31 \pm 0.089$ & .0000003 & $1.13 \pm 0.083$ & $2.23 \pm 0.226$ & .001 \\
\hline p-STAT3 $3_{\mathrm{tyr}} / \mathrm{STAT} 3$ & $0.13 \pm 0.024$ & $1.23 \pm 0.121$ & .0003 & $0.96 \pm 0.420$ & $2.57 \pm 0.520$ & .03 \\
\hline p-STAT3 ${ }_{\text {ser }} /$ STAT3 & $0.77 \pm 0.079$ & $2.38 \pm 0.260$ & .0002 & $0.54 \pm 0.045$ & $2.18 \pm 0.381$ & .002 \\
\hline p-STAT $5_{\text {tyr }} /$ STAT5-A & $0.80 \pm 0.119$ & $0.87 \pm 0.165$ & .60 & $1.28 \pm 0.223$ & $1.72 \pm 0.676$ & .52 \\
\hline \multirow[t]{3}{*}{ p-STAT $5_{\mathrm{tyr}} / \mathrm{STAT} 5-\mathrm{B}$} & $0.59 \pm 0.052$ & $0.65 \pm 0.116$ & .55 & $0.87 \pm 0.129$ & $0.93 \pm 0.145$ & .76 \\
\hline & \multicolumn{3}{|c|}{ Baseline } & \multicolumn{3}{|c|}{ Reperfusion } \\
\hline & RIPC & No RIPC & & RIPC & No RIPC & \\
\hline $\mathrm{p}-\mathrm{PKC} \alpha / \beta / \mathrm{PKC} \alpha$ & $1.17 \pm 0.065$ & $1.16 \pm 0.038$ & .92 & $1.37 \pm 0.074$ & $1.14 \pm 0.119$ & .11 \\
\hline p-p38/p38 & $1.26 \pm 0.241$ & $1.81 \pm 0.333$ & .18 & $1.04 \pm 0.168$ & $1.03 \pm 0.104$ & .96 \\
\hline p-VASP/VASP & $0.41 \pm 0.063$ & $0.51 \pm 0.076$ & .30 & $0.59 \pm 0.114$ & $0.47 \pm 0.060$ & .37 \\
\hline p-eNOS/eNOS & $2.28 \pm 0.189$ & $2.07 \pm 0.317$ & .55 & $0.87 \pm 0.214$ & $1.27 \pm 0.311$ & .31 \\
\hline p-AKT/AKT & $0.47 \pm 0.055$ & $0.69 \pm 0.148$ & .17 & $0.80 \pm 0.133$ & $0.70 \pm 0.139$ & .60 \\
\hline p-ERK1/2/ERK1/2 & $1.03 \pm 0.090$ & $1.62 \pm 0.319$ & .09 & $0.63 \pm 0.114$ & $0.77 \pm 0.132$ & .43 \\
\hline p-p70S6K/p70S6K & $1.10 \pm 0.164$ & $1.82 \pm 0.421$ & .11 & $1.35 \pm 0.242$ & $1.03 \pm 0.151$ & .28 \\
\hline p-GSK3 $\beta / G S K 3 \beta$ & $0.76 \pm 0.069$ & $0.86 \pm 0.045$ & .23 & $0.82 \pm 0.104$ & $0.85 \pm 0.071$ & .82 \\
\hline p-STAT $3_{\mathrm{tyr}} / \mathrm{STAT}$ & $0.37 \pm 0.042$ & $0.68 \pm 0.178$ & .11 & $0.64 \pm 0.094$ & $0.67 \pm 0.140$ & .87 \\
\hline p-STAT3 ${ }_{\text {ser }} /$ STAT3 & $1.27 \pm 0.095$ & $1.32 \pm 0.131$ & .75 & $0.70 \pm 0.068$ & $0.62 \pm 0.074$ & .45 \\
\hline p-STAT5 ${ }_{\text {tyr }} /$ STAT5-A & $1.09 \pm 0.136$ & $1.30 \pm 0.250$ & .48 & $0.82 \pm 0.167$ & $0.81 \pm 0.213$ & .96 \\
\hline p-STAT5 ${ }_{\mathrm{tyr}} / \mathrm{STAT}$-B & $1.15 \pm 0.143$ & $1.38 \pm 0.131$ & .25 & $0.97 \pm 0.149$ & $0.99 \pm 0.251$ & .95 \\
\hline
\end{tabular}

Baseline and reperfusion data are derived from separate gels and differ between upper and lower portions of table. Statistical comparisons made only for data from same gel. Ponceau staining used to normalize for protein loading of gels. RIPC, Remote ischemic preconditioning; $P K C \alpha$, protein kinase C $\alpha ; p 38$, p38 mitogen-activated protein kinase; $V A S P$, vasodilator-stimulated phosphoprotein; $e N O S$, endothelial nitric oxide synthase; $A K T$, protein kinase $\mathrm{B} ; E R K$, extracellular signal-regulated kinase; $p 70 S 6 K$, p70 ribosomal S6 protein kinase; GSK3 $\beta$, glycogen synthase kinase-3 $\beta$; STAT, signal transducer and activator of transcription; tyr, tyrosine; ser, serine.

\section{Interpretation of Results}

The present study is the first to report an association between a lack of RIPC effect and the lack of STAT5 activation, strengthening a causal role for STAT5 activation to mediate the cardioprotective effect by RIPC, such as was observed during isoflurane anesthesia. ${ }^{14}$ Previously, increased STAT5 phosphorylation was reported in human ischemic cardiomyopathy, but it was not related to function or protection. ${ }^{17}$ In the present study, propofol appeared to abolish, not only the cardioprotection evoked by RIPC, known to occur during isoflurane anesthesia, but also STAT5 activation. This supports the notion that STAT5 activation might not only be associated with, but causally involved in, cardioprotection.

Cardioprotection is highly complex and the cellular/subcellular localization of STAT5 and its targets to effect cardioprotection are currently unknown. However, we recently demonstrated in a pig model of myocardial ischemia/reperfusion the activation of STAT3 by ischemic postconditioning in mitochondria, along with better preservation of mitochondrial respiratory function and calcium retention capacity. ${ }^{18}$ This STAT3 activation was in pigs and not in humans. Also, it was in response to ischemic postconditioning and not to RIPC. Thus, we do not know whether the relative roles of STAT3 and STAT5 relate to species differences or differences in the conditioning protocols. The lipidsoluble anesthetic agent propofol (2,6-diisopropylphenol) has a chemical structure similar to that of phenol-based free radical scavengers such as vitamin $\mathrm{E}^{19}$ but does not interact with the adenosine triphosphate-sensitive potassium channels in vitro. ${ }^{19}$ Because small amounts of reactive oxygen species are necessary to evoke volatile anestheticinduced preconditioning, ${ }^{20}$ it is possible that propofol, by eliminating such reactive oxygen species, interferes with RIPC. Apparently, because propofol anesthesia was not associated with STAT5 activation and cardioprotection, it might interfere with the signal transduction pathway of RIPC somewhere upstream of STAT5.

The translation of cardioprotection to clinical routine is clearly an issue, and age, ${ }^{21}$ comorbidities, and medications are confounders. ${ }^{22,23}$ In our previous studies, the age and medication characteristics of patients with coronary artery 


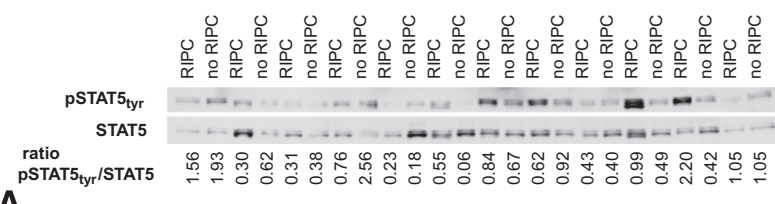

A

polyclonal antibodies

monoclonal antibodies

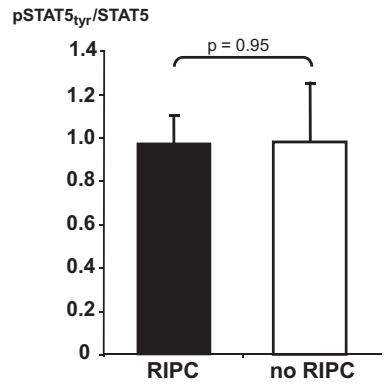

B

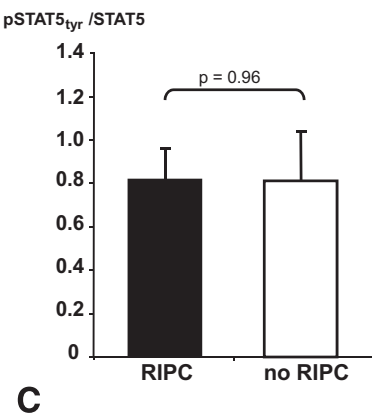

FIGURE 2. Comparison of phosphorylated $(p)$ and total signal transducer and activator of transcription (STAT) 5 content in left ventricular myocardial biopsy specimens obtained from patients with coronary artery disease undergoing remote ischemic preconditioning $(R I P C)$ or not (no RIPC) under propofol anesthesia. A, original Western blot; and B, C, mean \pm standard deviation. tyr, Tyrosine.

disease did not appear to interfere with the cardioprotection evoked by RIPC. ${ }^{1,6,13}$ To date, we also carefully excluded those with diabetes from our mechanistic studies, because diabetes interferes with cardioprotective signaling. ${ }^{24}$ $\beta$-Blockers might interfere with anesthesia-induced preconditioning $^{25}$; however, no such interference has been reported for calcium channel blockers, the use of which differed between the groups in our study. Of particular importance are the anesthetic regimens, which have hardly been standardized in RIPC trials and have usually have entailed mixed various anesthetic regimens and dosages. ${ }^{9-11}$ Zaugg and colleagues, ${ }^{11}$ for instance, in their doubleblind, randomized, controlled trial used propofol and 3 different opioids (fentanyl, sufentanil, or remifentanil) for induction and then isoflurane and 1 of the 3 opioids for maintenance of anesthesia during CPB and reperfusion and for the remainder of surgery. As noted in an editorial, ${ }^{12}$ this multitude of anesthetic variables raises the question of whether different results might have been obtained if isoflurane and only 1 opioid had been given throughout the induction of anesthesia, $\mathrm{CPB}$, and reperfusion.

According to our previous data, propofol might interfere with cardioprotective signaling. At the very least, we have confirmed in a new cohort of patients that propofol is not associated with the degree of cardioprotection that has been evoked by RIPC during isoflurane anesthesia in the same setting (ie, a 50\% reduction in accumulated postoperative troponin I release). Taking LV biopsy specimens per se did not increase the cTnI concentrations compared with our previous data from patients under propofol without LV biopsy specimens (RIPC with LV biopsies,
$273 \pm 184 \mathrm{ng} / \mathrm{mL} \times 72$ hours; RIPC without LV biopsies, $290 \pm 175 \mathrm{ng} / \mathrm{mL} \times 72$ hours, $P=.45 ;$ no RIPC with LV biopsies, $365 \pm 301 \mathrm{ng} / \mathrm{mL} \times 72$ hours; RIPC without LV biopsies, $324 \pm 210 \mathrm{ng} / \mathrm{mL} \times 72$ hours, $P=.41)^{13}$

Future studies are needed to assess whether RIPC not only decreases troponin concentrations as a surrogate marker of myocardial ischemia/reperfusion injury, but also improves the clinical outcome of patients undergoing coronary revascularization, and possibly also concomitant valve surgery. A quantitative estimate suggested that only patients with an infarct size of more than $20 \%$ of the left ventricle and with a magnitude of infarct size reduction from $75 \%$ to less than $40 \%$ of the area at risk would have a prognostic benefit. ${ }^{26}$ The Effect of Remote Ischaemic preConditioning on clinical outcomes in patients undergoing Coronary Artery Bypass Graft surgery (ERICCA) trial, a multicenter, randomized, double-blind, controlled, clinical trial, is underway to address this issue. ${ }^{27}$ The ERICCA trial has been scheduled to recruit in 27 tertiary centers within 2 years a total of 1610 high-risk patients undergoing $\mathrm{CABG}$ plus valve surgery using blood cardioplegia. However, the anesthetic regimen was not defined. Thus, taking together our data from the present and previous studies, ${ }^{1,13,14}$ although isoflurane permits cardioprotection to be recruited by RIPC ${ }^{28}$ propofol does not and might even actively interfere with the cardioprotective signaling of RIPC. Propofol appears to be a common denominator of all published clinical studies that reported no protection by RIPC. ${ }^{29}$ Our ultimate goal is to replace or enhance the cardioprotective effects of RIPC using a pharmacologic cardioprotectant. STAT5 appears to be an important target for such a cardioprotectant, and the potential abrogation of the effects of RIPC by propofol might help to identify such a cardioprotective agent.

\section{References}

1. Heusch G, Boengler K, Schulz R. Cardioprotection: nitric oxide, protein kinases, and mitochondria. Circulation. 2008;118:1915-9.

2. Przyklenk K, Bauer B, Ovize M, Kloner RA, Whittaker P. Regional ischaemic "preconditioning" protects remote virgin myocardium from subsequent sustained coronary occlusion. Circulation. 1993;87:893-9.

3. Heusch G, Schulz R. Remote preconditioning. J Mol Cell Cardiol. 2002;34 1279-81.

4. Hausenloy DJ, Mwamure PK, Venugopal V, Harris J, Barnard M, Grundy E, et al. Effect of remote ischaemic preconditioning on myocardial injury in patients undergoing coronary artery bypass graft surgery: a randomised controlled trial. Lancet. 2007;370:575-9.

5. Venugopal V, Hausenloy DJ, Ludman A, Di Salvo CM, Kolvekar S, Yap J, et al. Remote ischaemic preconditioning reduces myocardial injury in patients undergoing cardiac surgery with cold blood cardioplegia: a randomised controlled trial. Heart. 2009;95:1567-71.

6. Thielmann M, Kottenberg E, Boengler K, Raffelsieper C, Neuhaeuser M, Peters J, et al. Remote ischaemic preconditioning reduces myocardial injury after coronary artery bypass grafting with crystalloid cardioplegic arrest. Basic Res Cardiol. 2010;105:657-64.

7. Hoole SP, Heck PM, Sharples L, Khan SN, Duehmke R, Densem CG, et al. Cardiac remote ischemic preconditioning in coronary stenting (CRISP Stent) study: a prospective, randomized control trial. Circulation. 2009;119:820-7.

8. Rentoukas I, Giannopoulos G, Kaoukis A, Kossyvakis C, Raisakis K, Driva M, et al. Cardioprotective role of remote ischemic periconditioning in primary 
percutaneous coronary intervention. J Am Coll Cardiol Cardiovasc Intv. 2010;3: 49-55.

9. Rahman IA, Mascaro JG, Steeds RP, Frenneaux MP, Nightingale P, Gosling P, et al. Remote ischemic preconditioning in human coronary artery bypass surgery-from promise to disappointment? Circulation. 2010;122(suppl 1):S53-9.

10. Karuppasamy P, Chaubey S, Dew T, Musto R, Sherwood R, Desai J, et al. Remote intermittent ischaemia before coronary artery bypass graft surgery: a strategy to reduce injury and inflammation? Basic Res Cardiol. 2011;106:511-9.

11. Lucchinetti E, Bestmann L, Feng J, Freidank H, Clanachan A, Finegan BA, et al. Remote ischemic preconditioning applied during isoflurane inhalation provides no benefit to the myocardium of patients undergoing on-pump coronary artery bypass graft surgery. Anesthesiology. 2012;116:296-310.

12. Peters J. Remote ischaemic preconditioning of the heart: remote questions, remote importance, or remote preconditioning? Basic Res Cardiol. 2011;106: 507-9.

13. Kottenberg E, Thielmann M, Bergmann L, Heine T, Jakob H, Heusch G, et al. Protection by remote ischemic preconditioning during coronary artery bypass graft surgery with isoflurane but not propofol-a clinical trial. Acta Anaesthesiol Scand. 2011;56:30-8.

14. Heusch G, Musiolik J, Kottenberg E, Peters J, Jakob H, Thielmann M. STAT5 activation and cardioprotection by remote ischemic preconditioning in humans. Circ Res. 2012;110:111-5.

15. Pain T, Yang X-M, Critz SD, Yue Y, Nakano A, Liu GS, et al. Opening of mitochondrial KATP channels triggers the preconditioned state by generating free radicals. Circ Res. 2000;87:460-6.

16. Heinzel FR, Luo Y, Li X, Boengler K, Buechert A, Gracia-Dorado D, et al. Impairment of diazoxide-induced formation of reactive oxygen species and loss of cardioprotection in connexin 43 deficient mice. Circ Res. 2005;97:583-6.

17. Ng D, Court NW, dos Remedios C, Bogoyevitch M. Activation of signal transducer and activator of transcription (STAT) pathways in failing human hearts. Cardiovasc Res. 2003;57:333-46.

18. Heusch G, Musiolik J, Gedik N, Skyschally A. Mitochondrial STAT3 activation and cardioprotection by ischemic postconditioning in pigs with regional myocardial ischemia/reperfusion. Circ Res. 2011;109:1302-8.
19. Zaugg M, Lucchinetti E, Spahn DR, Pasch T, Garcia C, Schaub MC. Differential effects of anesthetics on mitochondrial K(ATP) channel activity and cardiomyocytes protection. Anesthesiology. 2002;97:15-23.

20. Müllenheim J, Ebel D, Frassdorf J, Preckel B, Thamer V, Schlack W. Isoflurane preconditions myocardium against infarction via release of free radicals. Anesthesiology. 2002;96:934-40.

21. Boengler K, Schulz R, Heusch G. Loss of cardioprotection with ageing. Cardiovasc Res. 2009;83:247-61.

22. Hausenloy DJ, Baxter G, Bell R, Botker HE, Davidson SM, Downey J, et al. Translating novel strategies for cardioprotection: the Hatter Workshop Recommendations. Basic Res Cardiol. 2010;105:677-86.

23. Longacre LS, Kloner RA, Arai AE, Baines CP, Bolli R, Braunwald E, et al. New horizons in cardioprotection: recommendations from the 2010 National Heart, Lung, and Blood Institute Workshop. Circulation. 2011;124:1172-9.

24. Tsang A, Hausenloy DJ, Mocanu MM, Carr RD, Yellon DM. Preconditioning the diabetic heart: the importance of Akt phosphorylation. Diabetes. 2005;54: 2360-4.

25. Lange M, Smul TM, Blomeyer CA, Redel A, Klotz KN, Roewer N, et al. Role of the beta I-adrenergic pathway in anesthetic and ischemic preconditioning against myocardial infarction in the rabbit heart in vivo. Anesthesiology. 2006;105: 503-10.

26. Miura T, Miki T. Limitation of myocardial infarct size in the clinical setting: current status and challenges in translating animal experiments into clinical therapy. Basic Res Cardiol. 2008;103:501-13.

27. Hausenloy DJ, Candilio L, Laing C, Kunst G, Pepper J, Kolvekar S, et al. ERICCA Trial Investigators. Effect of remote ischemic preconditioning on clinical outcomes in patients undergoing coronary artery bypass graft surgery (ERICCA): rationale and study design of a multi-centre randomized doubleblinded controlled clinical trial. Clin Res Cardiol. 2012;101:339-45.

28. Kehl F, Krolikowski JG, Mraovic B, Pagel PS, Warltier DC, Kersten JR. Is isoflurane-induced preconditioning dose related? Anesthesiology. 2002;96: 675-80.

29. Heusch G. Cardioprotection: changes and challenges of its translation to the clinic. Lancet. 1993;381:166-75. 